\title{
EPIDEMIOLOGICAL PANORAMA OF CHIKUNGUNYA FEVER IN BRAZIL ON THE FIRST SEMESTER OF 2020
}

Maria Laura Cabral Dantas ${ }^{1, \star}$, Maria Julimere Alexandre Neres ${ }^{1}$, Thaynara Sarmento Oliveira de Almeida ${ }^{1}$, Tereza Patrícia Acebey Crespo ${ }^{1}$, Pablo Duarte Lima ${ }^{1}$

1.Centro Universitário de João Pessoa, João Pessoa (PB), Brazil.

*Corresponding author: marialaura.cabral@hotmail.com

\section{BACKGROUND}

The chikungunya fever is an arborvirus disease transmitted by Aedes mosquitoes that were contaminated by the CHIKV virus, originated in Africa. The infection causes a sudden fever syndrome which is debilitating due to the manifestations on the joints that affect about $80 \%$ of the patients, which may last for many months or even years. It is considered a challenge for the public health nowadays.

\section{MATERIALS AND METHODS}

An ecological study in which the incidence, lethality and mortality rates of individuals on suspicion of chikungunya in notified geographic regions in Brazil were analyzed, during the first half of the year of 2020, by the Information System of Notification Grievances (SINAN).

\section{RESULTS}

The number of chikungunya notifications in Brazil until the June of 2020 was of 48,316 (the incidence equals 23 cases for every 10,000 inhabitants). The most affected regions were Northeast (48.3 cases/100,000 inhabits) and Southeast (21.1 cases/100,000 inhabitants). Followed by the North (4.9 cases/100,000 inhabitants), Center-West (4.2 cases/100,000 inhabitants) and South regions (1.8 case/100,000 inhabitants). In relation to the confirmed numbers acquired, the Northeast Region presented the highest number (8), followed by the Southeast (2) and Center-West regions (1). In the remaining regions, there were not any death registrations by chikungunya on that time period. The lethality rates per region were: Center-West $(0.14 \%)$, Northeast $(0.02 \%)$, Southeast $(0.01 \%)$, North $(0 \%)$, and South $(0 \%)$. This way, it is possible to attribute a higher incidence of cases on the Northeast due to the warm and humid climate, that is specific to the region, which contributes to the vector reproduction on the first half of the year as well as the loosened preventive manners for combating the vector mosquito.

\section{CONCLUSION}

With the epidemiological analysis of the current study, it is possible to conclude that the tropical climate of the Northeast Region appears to be one of the main factors in favor to the increased incidence of the chikungunya fever on the region, associated to the lack of schooling and the poor local infrastructure, that contributes to the difficult approach into combating the disease. By the time being, the comparatives of the lethality rates did not show any significant differences among the regions, even though it was the highest in the center-west region, which was probably in regards to the diagnosis challenges and the subnotification of the illness. 